\title{
Supporing Information
}

\section{Enhanced Dissolution of Liquid Microdroplets in the Extensional Creeping Flow of a Hydrodynamic Trap}

Adil Mustafa, ${ }^{\dagger}$ Ahmet Erten, ${ }^{*, \dagger}$ R. Armaghan Ayaz, ${ }^{\dagger}$ Oğuz Kayıllığ̆lu, ${ }^{\dagger}$ Aysenur Eser, ${ }^{\dagger}$ Mustafa Eryürek, ${ }^{\dagger}$ Muhammad Irfan, ${ }^{\ddagger}$ Metin Muradoglu, ${ }^{*, \ddagger}$ Melikhan

$$
\text { Tanyeri, }{ }^{*}, \text { and Alper Kiraz }{ }^{*} \dagger, \S
$$

$\dagger$ Department of Physics, Koç University, 34450 Sariyer, Istanbul, Turkey

$\ddagger$ Department of Mechanical Engineering, Koç University, 34450 Sariyer, Istanbul, Turkey

IDepartment of Electrical and Electronics Engineering, Istanbul Sehir University, 34662

Uskudar, Istanbul, Turkey

$\S$ Department of Electrical and Electronics Engineering, Koç University, 34450 Sariyer, Istanbul, Turkey

E-mail: ahmeterten@gmail.com; mmuradoglu@ku.edu.tr; melikhantanyeri@sehir.edu.tr; akiraz@ku.edu.tr 


\section{Channel Thickness Measurement}

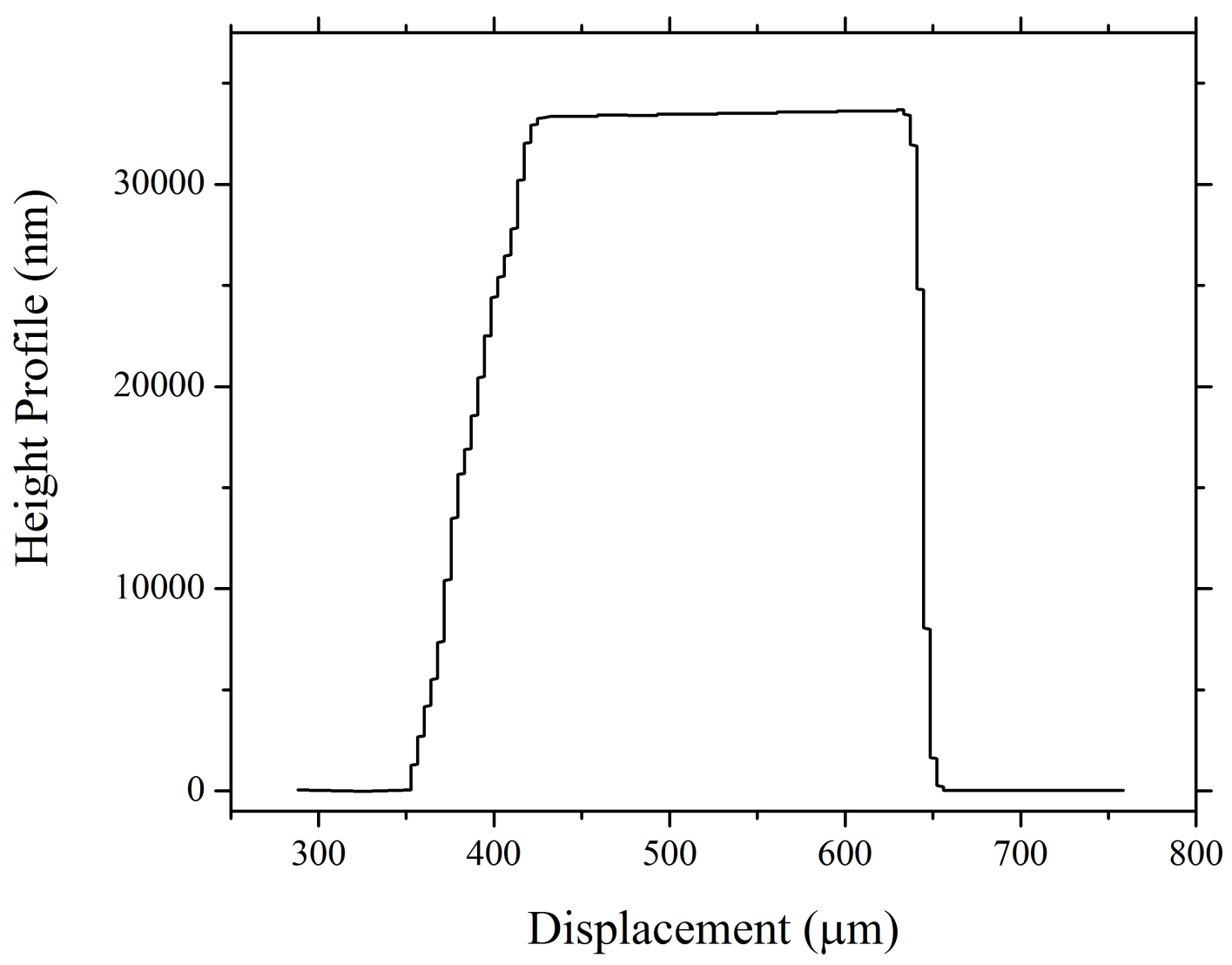

Figure S1: Surface profile showing the step height on the silicon mold used for the fluidic layer. 


\section{Péclet and Sherwood Numbers}

Péclet and Sherwood numbers calculated for data points shown in Fig.s 3-5. Péclet numbers, $P e$, are calculated using $P e=U R / D$ where $U, R$, and $D$ are the free stream velocity, droplet radius and diffusion coefficient for the droplet liquid in the host fluid. Sherwood numbers, Sh, ae calculated using Eq. 2 or 3 depending on the value of Pe. The discontinuity in some plots is due to the discontinuit between Eq.s 2 and 3 that are used for $1 \leq P e \leq 10$ and $10<P e \leq 1000$, respectively.
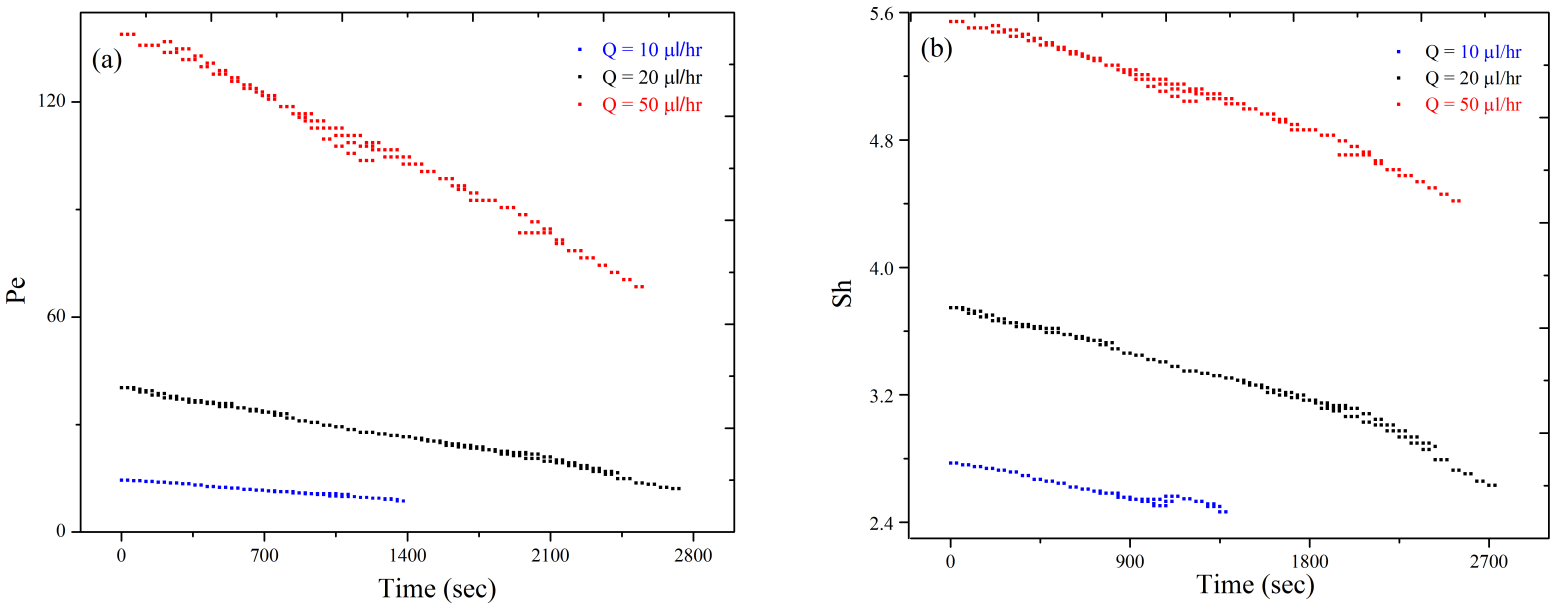

Figure S2: Péclet (a) and Sherwood (b) numbers calculated for data points shown in Figure 3, obtained with benzyl benzoate microdroplets in DI water containing $10 \mathrm{mM}$ AOT surfactant.
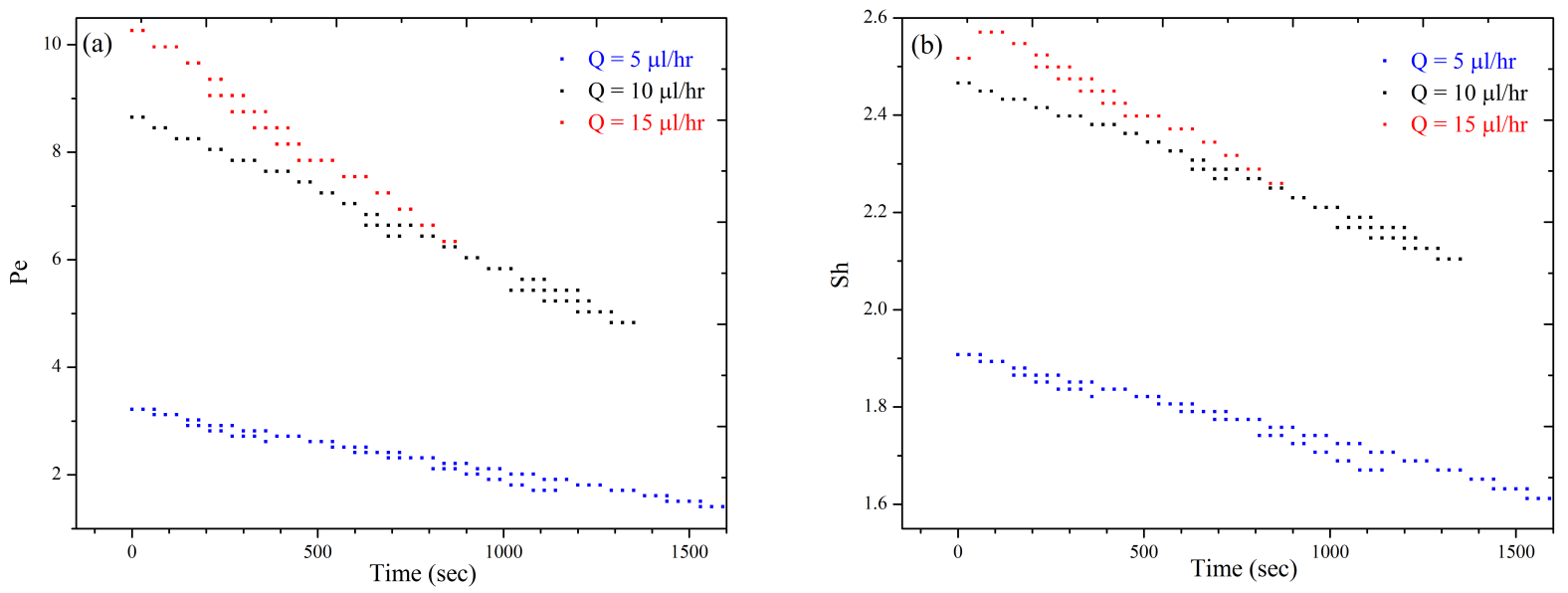

Figure S3: Péclet (a) and Sherwood (b) numbers calculated for data points shown in Figure 4, obtained with benzyl benzoate microdroplets in DI water containing $10 \mu \mathrm{M}$ AOT surfactant. 

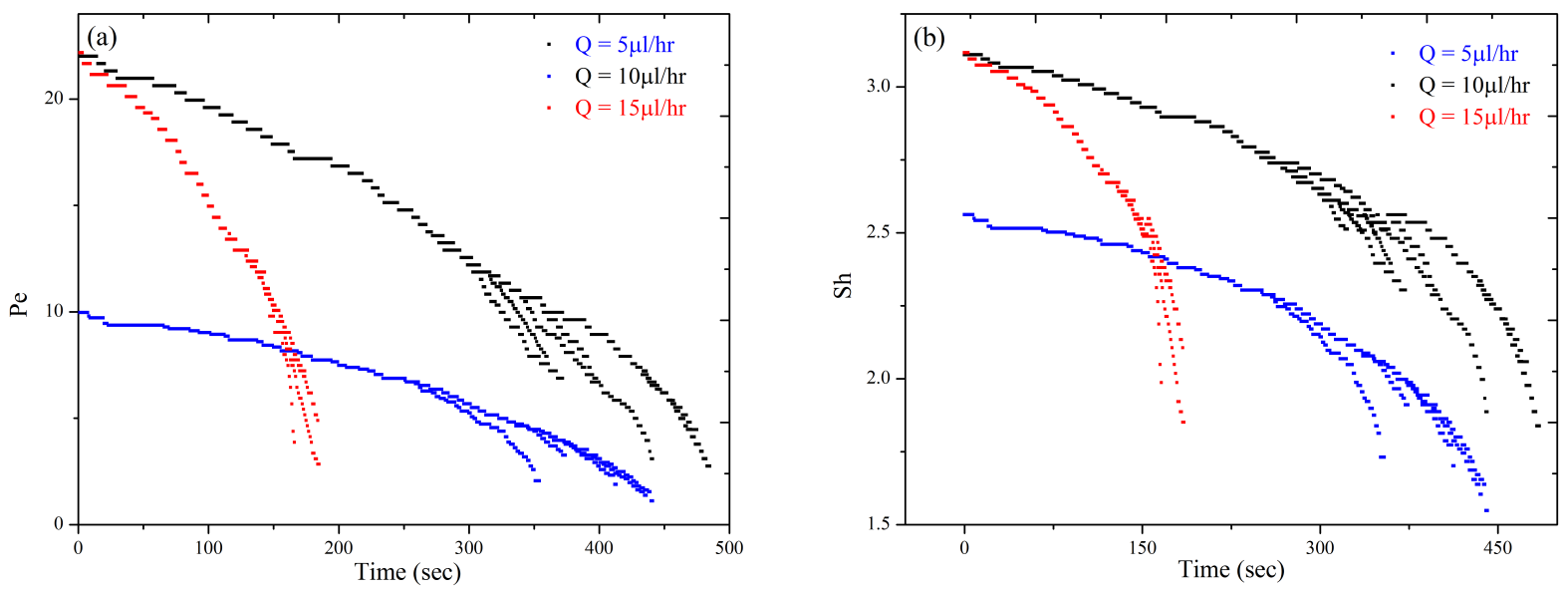

Figure S4: Péclet (a) and Sherwood (b) numbers calculated for data points shown in Figure 5, obtained with n-decanol microdroplets in DI water containing $10 \mathrm{mM}$ AOT surfactant.

\section{Movie Captions}

Movie S1: Dissolution of a hydrodynamically trapped benzyl benzoate microdroplet in DI water containing $10 \mathrm{mM}$ AOT surfactant at a flow rate of $Q=50 \mu \mathrm{L} / \mathrm{hr}$. Video consists of 52 images recorded with $30 \mathrm{~s}$ interval.

Movie S2: Dissolution of a hydrodynamically trapped benzyl benzoate microdroplet in DI water containing $10 \mu \mathrm{M}$ AOT surfactant at a flow rate of $Q=5 \mu \mathrm{L} / \mathrm{hr}$. Video consists of 72 images recorded with $30 \mathrm{~s}$ interval.

Movie S3: Dissolution of a hydrodynamically trapped n-decanol microdroplet in DI water containing $10 \mathrm{mM}$ AOT surfactant at a flow rate of $Q=10 \mu \mathrm{L} / \mathrm{hr}$. Video consists of 102 images recorded with $1 \mathrm{~s}$ interval. 